EXTENDED REPORT

\title{
Sensitivity to change of AIMS2 and AIMS2-SF components in comparison to M-HAQ and VAS-pain
}

\author{
E Taal, J J Rasker, R P Riemsma
}

Ann Rheum Dis 2004;63:1655-1658. doi: 10.1136/ard.2003.014522

See end of article for authors' affiliations

.....................

Correspondence to: Dr E Taal, University of Twente, Faculty of

Behavioural Sciences, Department of Communication Studies, PO Box 217, $7500 \mathrm{AE}$ Enschede, Netherlands; e.taal@utwente.nl

Accepted

16 February 2004
Objective: To examine sensitivity to change of Dutch versions of AIMS2 (arthritis impact measurement scales-2) and AIMS2-SF (short form) components, in comparison with M-HAQ (modified health assessment questionnaire) and the $100 \mathrm{~mm}$ visual analogue scale for pain (VAS-pain) in patients with rheumatoid arthritis.

Methods: 218 patients participated in a study on patient education. Participants completed the Dutch AIMS2, M-HAQ, and VAS-pain at baseline and after one year; 165 completed both assessments. The education programme did not have any effect on health status. Patients were classified according to change over one year in their responses to the AIMS2 question about general health perception: improved health $(n=32)$, no change $(n=101)$, and poorer health $(n=32)$. Changes in scores over one year were tested with paired $t$ tests, and standardised response means were calculated for AIMS2 and AIMS2-SF components, M-HAQ total score, and VAS-pain in the three classifications of change in health perception. Results: AIMS2 and AIMS2-SF physical, symptom, and affect components showed similar sensitivity to change. The physical and symptom components performed better than M-HAQ and VAS-pain. AIMS2 and AIMS2-SF social interaction and role components were not sensitive to changes in general health perception. The role component was only applicable in 63 patients, because the others were unemployed, disabled, or retired.

Conclusions: AIMS2-SF is a good alternative to the AIMS2 long form for the assessment of health status in rheumatoid arthritis, and is preferable to M-HAQ and VAS-pain. Use of the AIMS2-SF makes it easier and less costly to collect data and reduces the burden on patients.
$\mathrm{T}$ he arthritis impact measurement scales-2 (AIMS2) is a reliable and valid self report questionnaire with 12 scales to assess five components of health status in patients with arthritis: physical, symptom (pain), affect, social interaction, and role components. ${ }^{1}$ Completion of the questionnaire is a burden for many patients because of its length ( 57 items). This length also limits its use in clinical research and in routine practice to monitor patients.

Guillemin et al developed a short form of the AIMS2 (AIMS2-SF). ${ }^{2}$ The number of items in the AIMS2-SF was reduced by $54 \%$, from 57 to 26 , and it assesses the same five components as the long form AIMS2. Studies on patients with rheumatoid arthritis in France and Norway showed AIMS2-SF to be as reliable, valid, and sensitive to change as the AIMS2 long form. ${ }^{2}{ }^{3}$ The AIMS2-SF was also shown to be a reliable and valid instrument among patients with osteoarthritis in the USA. ${ }^{4}$ We have constructed Dutch versions of the AIMS2 (both long and short form) and have shown these to be reliable and valid measures of health status among patients with rheumatoid arthritis. ${ }^{56}$ However, one important property of health status scales-responsiveness or sensitivity to change-has not been assessed in our studies with the Dutch short and long versions of the AIMS2.

Our aim in this study was to examine sensitivity to change in perceived health over a one year period for components of the Dutch versions of AIMS2 and AIMS2-SF among patients with rheumatoid arthritis. We also compared the sensitivity to change in the AIMS2 and AIMS2-SF physical and symptom components with other short measures of physical function (the modified health assessment questionnaire (M-HAQ)) and pain (the $100 \mathrm{~mm}$ visual analogue scale (VAS-pain) $).^{7-9}$

\section{METHODS \\ Patients}

Data were used from a study on patient education for patients with rheumatoid arthritis..$^{10}$ All outpatients with this diagnosis (according to the 1987 American College of Rheumatology criteria) from the clinics of seven rheumatologists from two hospitals were asked by their rheumatologists to participate in a study on education for arthritis patients. ${ }^{11}$ Of 825 patients, 238 returned a form stating that they agreed to participate. These participants were then randomly assigned to three groups: group education with participation of a significant other (in most cases the spouse); group education for patients only; and a control group. A composite questionnaire was posted to each participating patient at baseline. In all, 218 respondents returned the questionnaires at baseline. Patients were asked to fill out questionnaires again immediately after the intervention, and after six and 12 months. For this study we used data from the baseline assessment and from the assessment after 12 months. For further details, see Riemsma et al. ${ }^{10}$

\section{Measures}

AIMS2 and AIMS2-SF

All participants completed the Dutch AIMS2 questionnaire. ${ }^{15}$ All items in the Dutch AIMS2 are measured on five point Likert scales scored from 1 to 5 . To obtain scale scores for the AIMS2 scales, the scores on the individual items in each scale

Abbreviations: AIMS2, arthritis impact measurement scales-2; AIMS2$\mathrm{SF}$, arthritis impact measurement scales-2, short form; $M-H A Q$, modified health assessment questionnaire; $M P Q, M c G i l l$ pain questionnaire; SF-36, short form 36-item general health questionnaire; SRM, standardised response mean; VAS, visual analogue scale 


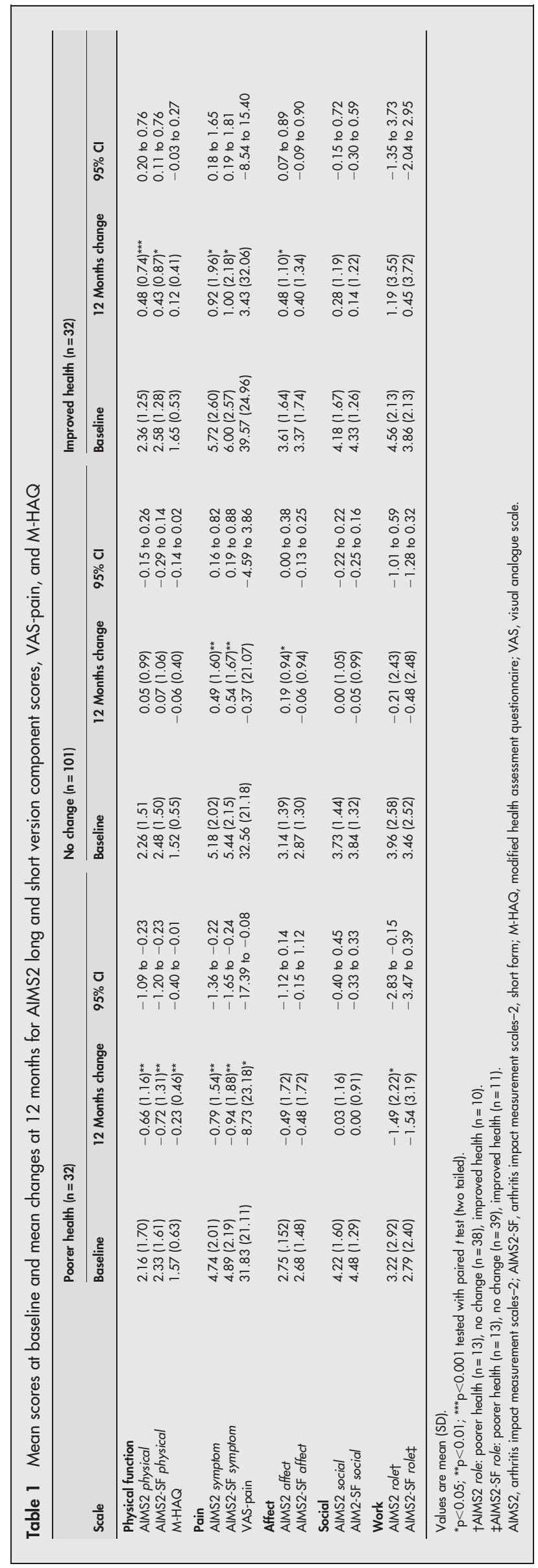

are summed. The result is then converted into a score ranging from 0 (good health) to 10 (poor health). AIMS2 and AIMS2SF component scores for physical, symptom (pain), affect, social interaction, and role components were calculated.

With regard to assessing arthritis pain, we computed scores for the modified symptom component by replacing item 42 "How often did your pain make it difficult for you to sleep?" by item 38 "How would you describe the arthritis pain you usually had?" as suggested by Havaardsholm and colleagues. ${ }^{3}$ The Dutch version of the modified symptom component showed better agreement with AIMS2 long form and improved validity in comparison with the original AIMS2SF symptom component. ${ }^{5}$

For social interaction we computed scores for a modified social interaction component by replacing item 33 "Go to a meeting of a church, club, team or other group" with item 31 "Visit friends or relatives at their homes." This modified social interaction component had improved internal consistency and showed better agreement with AIMS2 long form than the original AIMS2-SF social interaction component. ${ }^{5}$

AIMS2 component scores are the averages of the scores of the corresponding scales. AIMS2-SF component scores are calculated by summing the individual item scores, and converting these sum scores into scores ranging from 0 to 10 .

\section{General health perception}

One Likert-type question to assess general health perception is included in the AIMS2 questionnaire: "In general would you say that your health is excellent, good, fair or poor?". Scores ranged from 1 (excellent) to 4 (poor).

\section{M-HAQ}

All participants completed a Dutch version of the modified health assessment questionnaire (M-HAQ). ${ }^{78}$

\section{VAS-pain}

Pain was assessed with a $100 \mathrm{~mm}$ visual analogue scale, ranging from 0 (no pain) to 100 (severe pain).

\section{Statistics}

All analyses were carried out on the data from patients who completed the questionnaires at baseline and after 12 months.

To examine sensitivity to change of AIMS2 short and long form components in comparison with M-HAQ and VAS-pain, changes in patients' general health perception over 12 months (baseline minus 12 months) were used as an indicator of change in health status. Patients were classified into three groups: improved health (change score $>0$ ), no change (change score $=0$ ), and poorer health (change score $<0$ ). Changes between baseline and 12 months in AIMS2 short and long form components were tested with paired $t$ tests in the three groups of change in health status. In each of the three groups, standardised response means (SRM) were calculated as the ratio of the mean change between baseline and 12 months to the standard deviation (SD) of that change for AIMS2 long and short form components, M-HAQ, and VAS-pain scores. Ninety five per cent confidence intervals (CI) for the SRM were calculated under the assumption that change scores followed a normal distribution and therefore the distribution of the SRM could be approximated by a normal distribution, with a mean of zero and a standard deviation of 1 divided by the square root of the sample size. ${ }^{3}{ }^{12}$

\section{RESULTS}

The questionnaires were completed by 165 patients at baseline and at 12 months. The mean (SD) age of the patients was 56.6 (9.5) years (range 28 to 70 ), and the mean disease duration, 11.7 (9.8) years (range 0 to 53 ); $12.1 \%$ of 
Table 2 Sensitivity to change of AIMS2 long and short version component scores, VAS-pain, and M-HAQ for changes in perceived health status over 12 months

\begin{tabular}{|c|c|c|c|c|c|c|}
\hline \multirow[b]{2}{*}{ Scale } & \multicolumn{2}{|c|}{ Poorer health $(n=32)$} & \multicolumn{2}{|c|}{ No change $(n=101)$} & \multicolumn{2}{|c|}{ Improved health $(n=32)$} \\
\hline & SRM & $95 \% \mathrm{Cl}$ & SRM & $95 \% \mathrm{Cl}$ & SRM & $95 \% \mathrm{Cl}$ \\
\hline $\begin{array}{l}\text { Physical function } \\
\text { AIMS2 physical } \\
\text { AIMS2-SF physical } \\
\text { M-HAQ }\end{array}$ & $\begin{array}{l}-0.63 \\
-0.63 \\
-0.55\end{array}$ & $\begin{array}{l}-0.99 \text { to }-0.27 \\
-0.99 \text { to }-0.27 \\
-0.90 \text { to }-0.20\end{array}$ & $\begin{array}{r}0.05 \\
0.07 \\
-0.14\end{array}$ & $\begin{array}{l}-0.15 \text { to } 0.25 \\
-0.13 \text { to } 0.27 \\
-0.34 \text { to } 0.06\end{array}$ & $\begin{array}{l}0.46 \\
0.38 \\
0.29\end{array}$ & $\begin{array}{r}0.10 \text { to } 0.82 \\
0.02 \text { to } 0.74 \\
-0.07 \text { to } 0.65\end{array}$ \\
\hline $\begin{array}{l}\text { Pain } \\
\text { AIMS2 symptom } \\
\text { AIMS2-SF symptom } \\
\text { VAS-pain }\end{array}$ & $\begin{array}{l}-0.45 \\
-0.49 \\
-0.35\end{array}$ & $\begin{array}{l}-0.81 \text { to }-0.09 \\
-0.85 \text { to }-0.13 \\
-0.71 \text { to } 0.01\end{array}$ & $\begin{array}{r}0.28 \\
0.28 \\
-0.01\end{array}$ & $\begin{array}{r}0.08 \text { to } 0.48 \\
0.08 \text { to } 0.48 \\
-0.21 \text { to } 0.19\end{array}$ & $\begin{array}{l}0.52 \\
0.52 \\
0.14\end{array}$ & $\begin{array}{r}0.16 \text { to } 0.88 \\
0.16 \text { to } 0.88 \\
-0.22 \text { to } 0.50\end{array}$ \\
\hline $\begin{array}{l}\text { Affect } \\
\text { AIMS2 affect } \\
\text { AIMS2-SF affect }\end{array}$ & $\begin{array}{l}-0.41 \\
-0.39\end{array}$ & $\begin{array}{l}-0.77 \text { to }-0.05 \\
-0.75 \text { to }-0.03\end{array}$ & $\begin{array}{r}0.16 \\
-0.05\end{array}$ & $\begin{array}{l}-0.04 \text { to } 0.36 \\
-0.25 \text { to } 0.15\end{array}$ & $\begin{array}{l}0.40 \\
0.32\end{array}$ & $\begin{array}{r}0.04 \text { to } 0.76 \\
-0.04 \text { to } 0.68\end{array}$ \\
\hline $\begin{array}{l}\text { Social } \\
\text { AIMS2 social } \\
\text { AIM2-SF social }\end{array}$ & $\begin{array}{l}0.03 \\
0.00\end{array}$ & $\begin{array}{l}-0.33 \text { to } 0.39 \\
-0.36 \text { to } 0.36\end{array}$ & $\begin{array}{r}0.00 \\
-0.05\end{array}$ & $\begin{array}{l}-0.20 \text { to } 0.20 \\
-0.25 \text { to } 0.15\end{array}$ & $\begin{array}{l}0.25 \\
0.14\end{array}$ & $\begin{array}{l}-0.11 \text { to } 0.61 \\
-0.22 \text { to } 0.50\end{array}$ \\
\hline $\begin{array}{l}\text { Work } \\
\text { AIMS2 role† } \\
\text { AIMS2-SF roleł }\end{array}$ & $\begin{array}{l}-0.56 \\
-0.53\end{array}$ & $\begin{array}{l}-1.10 \text { to }-0.02 \\
-1.07 \text { to } 0.01\end{array}$ & $\begin{array}{l}-0.08 \\
-0.17\end{array}$ & $\begin{array}{l}-0.40 \text { to } 0.24 \\
-0.49 \text { to } 0.15\end{array}$ & $\begin{array}{l}0.44 \\
0.16\end{array}$ & $\begin{array}{l}-0.18 \text { to } 1.08 \\
-0.43 \text { to } 0.75\end{array}$ \\
\hline
\end{tabular}

Values are standardised response means with $95 \%$ confidence intervals.

†AIMS2 role: poorer health $(n=13)$, no change $(n=38)$, improved health $(n=10)$

fAIMS2-SF role: poorer health $(n=13)$, no change $(n=39)$, improved health $(n=11)$

AIMS2, arthritis impact measurement scales-2; AIMS2-SF, arthritis impact measurement scales-2, short form; M-HAQ, modified health assessment questionnaire;

SRM, standardised response mean; VAS, visual analogue scale.

the patients had early rheumatoid arthritis (disease duration $\leqslant 2$ years) and $60.6 \%$ of the patients were female.

Patients were classified into three groups based on changes over 12 months in general health perception: improved health $(\mathrm{n}=32)$, no change $(\mathrm{n}=101)$, and poorer health $(\mathrm{n}=32)$.

In the "poorer health" group, scores on all three measures of physical function were worse after 12 months $(p<0.01)$, while in the "no change" group there were no significant changes in the scores (table 1). In the "improved health" group, scores improved $(\mathrm{p}<0.001)$ on AIMS2 and AIMS2-SF physical components over 12 months, but scores on the MHAQ after 12 months were not significantly different from baseline.

Scores on all three measures of pain were significantly worse after 12 months in the "poorer health" group (table 1). In the "improved health" group, scores on the two AIMS2 pain measures (symptom components) improved significantly over 12 months, but the VAS-pain scores did not change over this period. Patients who did not perceive their health to be changed after 12 months compared with baseline had no significant change in VAS-pain scores, but they had improved scores on the AIMS2 pain measures.

Affect scores for both versions of AIMS2 were worse in the "poorer health" group after 12 months, but the changes were not significant. Patients in the "no change" group had improved affect scores on AIMS2 but not on AIMS2-SF $(\mathrm{p}<0.05)$. In the "improved health" group, affect scores on AIMS2 also improved significantly $(p<0.05)$, but not on AIMS2-SF.

There was no change in AIMS2 and AIMS2-SF social interaction scores in any of the three groups over 12 months.

The items of the role component were only applicable to 63 patients, because the other patients were unemployed, disabled, or retired. Only the AIMS2 role component scores in the "poorer health" group changed significantly over 12 months $(\mathrm{p}<0.05)$.

SRMs for the AIMS2 short and long version component scores were very similar in all three groups (table 2). SRMs for M-HAQ and VAS-pain were smaller than the SRMs for the comparable AIMS2 physical and symptom components in the "poorer health" and "improved health" groups. In the "improved health" group, the SRMs for VAS-pain and MHAQ were not significantly different from zero (95\% confidence intervals include 0 ).

The AIMS2 long version affect component was more sensitive to changes in health perception than the short version; in the improved health group the SRM for the short version affect component was not significantly different from zero (the 95\% confidence interval included 0).

Neither the short nor the long versions of the AIMS2 social interaction component were sensitive to changes in perceived health (table 2).

The AIMS2 long version of the role component was somewhat more sensitive to changes in perceived health than the short version, but the items of the role component were only applicable to 13 patients in the "poorer health" group and 11 in the "improved health" group.

\section{DISCUSSION}

This study shows that the long and short versions of the AIMS2 physical, symptom, and affect components are sensitive to changes in perceived health over one year. The SRMs for the short and long versions were very similar. The social component of both versions was not sensitive to changes in perceived health. However, AIMS2 social component scores for the patients did not differ much from healthy controls. ${ }^{5}$ It is not possible to draw conclusions about the sensitivity to change of the role components of either version because these were only applicable to 13 patients in the "poorer health" group and 11 patients in the "improved health" group.

The AIMS2 long form has been shown to be sensitive to change in studies in the USA, France, and Sweden. ${ }^{13-15}$ However, as in our study, the Swedish and French studies also showed that the AIMS2 social component has low sensitivity to change. ${ }^{14}{ }^{15}$ The French and Norwegian versions of the AIMS2-SF had similar sensitivity to change as the long form AIMS2. ${ }^{23}$ 
VAS-pain and M-HAQ proved less sensitive to change than the related AIMS2 short and long components; and neither VAS-pain nor M-HAQ were sensitive to improvements in perceived health over one year. The Norwegian AIMS2 long and short physical component was shown to have similar sensitivity to change as the M-HAQ and the physical function scale of the SF-36. ${ }^{3}$ However in other studies, the M-HAQ was found to lack sensitivity to change ${ }^{16}{ }^{17}$ and to be worse at detecting treatment changes than the full HAQ. ${ }^{18}$

The VAS-pain was less sensitive to deterioration of health status than AIMS2 short and long versions and SF-36, but had greater sensitivity to improvements in the Norwegian study. ${ }^{3}$ Bellamy et al compared the sensitivity to change of eight self rating pain scales in patients with rheumatoid arthritis. ${ }^{9}$ All scales proved capable of detecting improvement after four weeks of treatment with oxaprozin. VAS-pain and other simple pain scales (the five point Likert scale, numerical rating scales, continuous chromatic analogue scales) were more sensitive to change than more complex pain scales such as the MPQ (McGill pain questionnaire).

A limitation of our own and other studies with the AIMS2SF is the use of data gathered with the long form of the AIMS2..$^{2-4}$ This may cause a "framing" effect and lead to an overestimation of the similarity between the two forms. ${ }^{23}$ The psychometric properties of the AIMS2-SF should also be investigated with data gathered by the short form on its own.

In this study we used self reported changes in general health as an indicator of true change to analyse sensitivity to change. Havaardsholm et $a l^{3}$ used self reported change in global disease activity as an indicator of the sensitivity to change of the AIMS2 long and short versions. Others assessed sensitivity to change in AIMS2 short or long versions following treatment with, for example, methotrexate or $\mathrm{DAB}_{486} \mathrm{IL}-2$ (a biological agent) which have proven clinical effects $^{2}{ }^{13}{ }^{15}$ On the one hand, the use of self reported change as an indicator limits the value of our results; both the AIMS2 and the perception of general health are self report measures, and it is to be expected that these scores are highly correlated. On the other hand, the use of self reported change in general health perception takes into account a general patients' perspective. Sensitivity to change of the Dutch AIMS2 short and long forms for specific interventions such as treatment with methotrexate or infliximab remains to be proven.

\section{Conclusions}

Our study indicates that the AIMS2-SF is a good alternative to the AIMS2 long form for the assessment of health status in rheumatoid arthritis. Use of the AIMS2-SF instead of the long form makes it easier and less costly to collect data and reduces the burden on patients. M-HAQ and VAS-pain are also very short measures, but AIMS2-SF is preferable for the assessment of physical function and pain. M-HAQ and VASpain were less sensitive to change in perceived health than AIMS2-SF.

\section{ACKNOWLEDGEMENTS}

This study was supported by grants from the Dutch League against Rheumatism. We wish to thank all our respondents. We also gratefully acknowledge the cooperation of the rheumatologists $\mathrm{Dr}$ H J Bernelot Moens, Dr J J M Festen, Dr C J Haagsma, Dr M W M Kruijsen, Dr M A F J van de Laar, and Dr J C M Oostveen.

\section{Authors' affiliations}

E Taal, Department of Communication Studies, University of Twente, Enschede, Netherlands

J J Rasker, Department of Rheumatology, Medisch Spectrum Twente Enschede, Netherlands

R P Riemsma, Centre for Reviews and Dissemination, University of York, York, UK

\section{REFERENCES}

1 Meenan RF, Mason JH, Anderson JJ, Guccione AA, Kazis LE. The content and properties of a revised and expanded arthritis impact measurement scales health status questionnaire. Arthritis Rheum 1992;35:1-10.

2 Guillemin F, Coste J, Pouchot J, Ghezail M, Bregeon C, Sany J. The AIMS2-SF: a short form of the arthritis impact measurement scales 2. French Quality of Life in Rheumatology Group. Arthritis Rheum 1997:40:1267-74.

3 Haavardsholm EA, Kvien TK, Uhlig T, Smedstad LM, Guillemin F. A comparison of agreement and sensitivity to change between AIMS2 and a short form of AIMS2 (AIMS2-SF) in more than 1000 rheumatoid arthritis patients. J Rheumatol 2000;27:2810-16.

4 Ren XS, Kazis L, Meenan RF. Short-form arthritis impact measurement scales 2: tests of reliability and validity among patients with osteoarthritis. Arthritis Care Res 1999;12:163-71.

5 Riemsma RP, Taal E, Rasker JJ, Houtman PM, Van Paassen HC, Wiegman O. Evaluation of a Dutch version of the AIMS2 for patients with rheumatoid arthritis. Br J Rheumatol 1996;35:755-60.

6 Taal E, Rasker JJ, Riemsma RP. Psychometric properties of a Dutch short form of the arthritis impact measurement scales 2 (Dutch-AIMS2-SF). Rheumatol 2003;42:427-34.

7 Taal E, Riemsma RP, Brus HLM, Seydel ER, Rasker JJ, Wiegman O. Group education for patients with rheumatoid arthritis. Patient Educ Couns 1993;20:177-87.

8 Pincus T, Callahan LF, Brooks RH, Fuchs HA, Olsen NJ, Kaye JJ. Self-report questionnaire scores in rheumatoid arthritis compared with traditional physical, radiographic, and laboratory measures. Ann Intern Med 1989;110:259-66.

9 Bellamy N, Campbell J, Syrotuik J. Comparative study of self-rating pain scales in rheumatoid arthritis patients. Curr Med Res Opin 1999;15:121-7.

10 Riemsma RP, Taal E, Rasker JJ. Group education for rheumatoid arthritis patients and their partners. Arthritis Care Res 2003;49:556-66.

11 Arnett FC, Edworthy SM, Bloch DA, McShane DJ, Fries JF, Cooper NS, et al. The American Rheumatism Association 1987 revised criteria for the classification of rheumatoid arthritis. Arthritis Rheum 1988;31:315-24.

12 Beaton DE, Hogg-Johnson S, Bombardier C. Evaluating changes in health status: reliability and responsiveness of five generic health status measures in workers with musculoskeletal disorders. J Clin Epidemiol 1997;50:79-93.

13 Anderson JJ, O'Neill A, Woodworth T, Haddad J, Sewell KL, Moreland LW. Health status response of rheumatoid arthritis to treatment with DAB486IL-2. Arthritis Care Res 1996;9:112-19.

14 Archenholtz B, Bjelle A. Reliability, validity, and sensitivity of a Swedish version of the revised and expanded arthritis impact measurement scales (AIMS2). J Rheumatol 1997;24:1370-7.

15 Pouchot J, Guillemin F, Coste J, Bregeon C, Sany J. Validity, reliability, and sensitivity to change of a French version of the arthritis impact measurement scales 2 (AIMS2) in patients with rheumatoid arthritis treated with methotrexate. J Rheumatol 1996;23:52-60.

16 Stucki G, Stucki S, Bruhlmann P, Michel BA. Ceiling effects of the health assessment questionnaire and its modified version in some ambulatory rheumatoid arthritis patients. Ann Rheum Dis 1995;54:461-5.

17 Serrano MAB, Fabregat JB, Garzon JO. Should the MHAQ ever be used? Ann Rheum Dis 1996;55:271.

18 Wolfe $F$. Which HAQ is best? A comparison of the HAQ, MHAQ and RA$H A Q$, a difficult 8-item HAQ (DHAQ) and a re-scored 20-item HAQ (HAQ20): analyses in 2491 rheumatoid arthritis patients following leflunomide initiation, J Rheumatol 2001;28:982-9. 